\title{
Sermón y literatura. La imagen del predicador en algunos sermones de la Nueva España
}

\author{
Ana Castaño Navarro
}

\begin{abstract}
Por una parte, el sermón novohispano puede ubicarse en el extremo más académico del cultivo de la lengua literaria; pero, por otra parte y al mismo tiempo, puede hacer pleno uso de los recursos de la oralidad, del teatro y hasta del periodismo. En estas páginas se hacen algunas reflexiones acerca del papel del sermón en la cultura y en la vida literaria novohispanas y se analiza su prestigio y su vitalidad como forma, así como el correspondiente orgullo profesional de quienes lo cultivaban. Asimismo, se muestran algunos ejemplos, extraídos de sermones del periodo colonial, que ilustran las ideas que predominaban en la Nueva España en torno al predicador y su oficio, mostrando algunos de los tópicos más significativos relacionados con la figura de este personaje de las letras que, en más de un aspecto, puede equipararse al ensayista de nuestros días.
\end{abstract}

Palabras Clave: literatura, Nueva España, predicación, comentario.

On the one hand, the sermon of the Mexican colonial period partakes of the more learned and academic aspects of literary language; but on the other hand it can also partake of the techniques of orality, drama and even journalism. This paper discusses the Sermon as a genre in the cultural and literary atmosphere of colonial Mexico, as well as the prestige and vitality acquired by this long established literary form -with the corresponding professional pride of those who cultivated it. Examples are drawn from sermons of this period, with images that portray some of the dominant ideas about the preacher in the Nueva España, whose work in more than one way resembles the modern essay. 

Ana Castaño

Instituto de Investigaciones Filológicas, UNAM

\section{Sermón y literatura. La imagen del predicador en algunos sermones de la Nueva España}

\section{El sermón y la vida literaria}

Tanta tinta ha corrido sobre los excesos conceptistas y culteranos de los predicadores "gerundianos", así como sobre la polémica entre partidarios y detractores de la elocuencia en el púlpito, que ha acabado por oscurecer una importante faceta de la producción literaria de los siglos XVII y XVIII. ${ }^{1}$ Así, tendemos a olvidar, o a ignorar por completo, la gran vitalidad que durante esos siglos tuvo el género del sermón en la vida literaria y cultural del mundo cristiano. Y tendemos a ello a pesar de los esfuerzos de algunos estudiosos que, durante las últimas décadas, han llamado nuestra atención sobre el poderoso atractivo literario que los sermones en nuestra lengua ejercieron sobre un público numeroso y diverso durante al menos tres siglos y, en consecuencia, el activo fermento que produjeron en distin-

${ }^{1}$ Ya lo decía, en 1956, el P. Félix Olmedo en su prólogo a los sermones de Dionisio Vázquez: "Hablar de la predicación española parece que es hablar de Fray Gerundio. El famoso predicador de Campazas es todavía para muchos, no una caricatura burlesca de los malos predicadores del tiempo del padre Isla, sino una figura simbólica de nuestra predicación, el predicador español de todos los tiempos pasados, presentes y futuros" (IX). 


\section{tos niveles de la lengua y de la creación literaria. ${ }^{2}$ No obstante, no deja de llamarnos hoy la atención el hecho de que, hace}

${ }^{2}$ Para el periodo medieval debemos sendos trabajos seminales, aunque de muy diferente extensión y enfoque, a Francisco Rico y a Pedro Cátedra. Del primero, Predicación y literatura en la España medieval, Cádiz, Universidad Nacional de Educación a Distancia, 1977; y del segundo, la edición de los sermones castellanos de Vicente Ferrer: Sermón, sociedad y literatura en la Edad Media. San Vicente Ferrer en Castilla (1411-1412), Salamanca: Junta de Castilla y León, 1994. Para los siglos XV al XVII en España, tenemos las ediciones e introducciones del P. Félix Olmedo a los sermones de fray Dionisio Vázquez (en 1956) y Francisco Terrones del Caño (en 1946) de la colección Clásicos Castellanos; también el Sermonario clásico de Miguel Herrero García, y el muy importante Preaching in the Spanish Golden Age, de Hillary Dansey Smith, Oxford, Oxford University Press, 1978. Por otra parte, contamos con la edición e introducción de la Censura de la elocuencia (Zaragoza, 1648), de José de Ormaza, hechas por Giuseppina Ledda, Madrid, El Crotalón, 1985. Asimismo están los varios estudios de Francis Cerdan (por ejemplo, la edición que hizo de los sermones de Paravicino: Fray Hortensio Paravicino. Sermones cortesanos, Madrid, Castalia-Comunidad de Madrid, 1994, y el artículo "Oratoria sagrada y reescritura en el Siglo de Oro: el caso de la homilía", Criticón, 79, 2000, 87-105. También contamos con el extenso estudio del lenguaje literario de Paravicino que debemos a Emilio Alarcos, "Los sermones de Paravicino", Revista de Filología Española, XXIV, 1937, 162-197 y 249-319. Además, y de manera más reciente, los interesados en la emblemática, a la vera de Marguerita Morreale, han estudiado la repercusión literaria de los jeroglíficos, vía la predicación, en obras como La pícara Justina. En los últimos años Félix Herrero Salgado concluyó otro trabajo de gran envergadura: los cuatro volúmenes de La oratoria sagrada en los siglos XVI y XVII, Fundación Universitaria Española, Madrid, 1996-2004. En lo que se refiere al sermón novohispano el panorama es más pobre; aquí son principalmente los historiadores quienes han recurrido — siempre desde la óptica de su disciplinaa la lectura más o menos sistemática de sermones publicados durante los siglos coloniales: Brian F. Connaughton, "El sermón, la folletería y la ampliación del mundo editorial mexicano, 1810-1854", Secuencia, nueva época, 39 (sep.-dic. 1997); Carlos Herrejón Peredo, "La oratoria en Nueva España", Relaciones, 57, 1994, 57-80; Jorge Alberto Manrique, "Retórica y Barroco". Respuesta de Jorge Alberto Manrique al discurso "La oratoria...", Relaciones, 57, 1994, 81-92; David Brading, Siete sermones guadalupanos (1709-1765), México, Centro de Estudios de Historia de México Condumex, 1994 [1993]; y, más recientemente, Alicia Mayer también con algunos trabajos sobre el sermón novohispano como vehículo del guadalupanismo y de la ideología de la contrarreforma. En el terreno de los estudios literarios, sólo durante los últimos años ha surgido el interés por los sermones novohispanos. Perla Chinchilla Pawling publicó en 2004 un libro dedicado a la historia del sermón como género literario, donde analiza, partiendo de una rica documentación, su ubicación entre la oralidad y la escritura: De la Compositio Loci a la República de las letras. Predicación jesuita en el siglo XVII novohispano, Universidad Iberoamericana, 
apenas 30 años, uno de estos estudiosos pioneros del campo se sintiera en la necesidad de aclarar que, además de ser una función religiosa, el sermón constituye un género. ${ }^{3}$

Sabemos que una de las principales funciones religiosas desempeñadas por el sermón fue siempre la de ser una especie de "despertador" de conciencias (título que ostenta más de una obra de edificación en la época); pues bien, como género literario — situado en el encuentro entre oralidad y literariedad-, podríamos decir que el sermón fungió también como despertador de conciencias linguiísticas y literarias. En relación con dicho tema, es significativo el hecho de que la transmisión textual del género, en más de una ocasión, refleja la asociación del sermón con el uso y valoración literaria de las lenguas vernáculas - Francisco Rico ha recordado que los primeros testimonios escritos de nuestra lengua se encuentran precisamente al margen de unos sermones de san Agustín-. Por otra parte, no es extraño que encontremos, encuadernados junto a colecciones de sermones y tratados de elocuencia sagrada, o incluso formando parte de éstos, escritos dedicados al elogio de la lengua vulgar, reflexiones sobre la traducción, la lengua literaria, sobre el estilo, el uso y la norma. José de Ormaza (1648) se queja de que los españoles piensan que el latín es más elegante que su propia lengua porque — dice- "nadie estima lo de casa" (Censura, 50). Y antes que él, Bartolomé Jiménez Patón, autor de una de las primeras gramáticas renacentistas, y autor también de uno de los primeros manuales de predicación impresos en español, publica éste junto con una apología del

\footnotetext{
México, 2004. Empieza también a ser estudiado el aspecto literario de los sermones novohispanos en algunos trabajos de tesis en la Facultad de Filosofía y Letras de la UNAM.

3 "In few other literary genres (and I believe that the sermon is a genre as well as a religious function) is the personal voice so difficult to distinguish from the persona" (Smith, Preaching, viii, subrayado mío).
} 
uso de la lengua vulgar como lengua literaria, escrita por Fernando Ballesteros Saavedra. ${ }^{4}$

En el siglo XVII, el célebre predicador cortesano fray Hortensio Paravicino, amigo de Góngora, haciéndose eco de las polémicas anticulteranas, defiende así la introducción de novedades en la lengua y en la estructura de los sermones: "Haber hallado, después de tantos, algo nuevo en esta lengua [...] no es formar otro idioma, sino venerar tanto el vulgar castellano nuestro, que nos prometemos de él la sublimidad clásica de los otros" (Sermones, 224). Otro ejemplo que subraya esta tradición es del último cuarto del siglo XVIII: Pedro Antonio Sánchez Vaamonde incluye, en su Discurso sobre la elocuencia sagrada en España (1778), un hermoso tratado literario que habla sobre el estilo, la lengua literaria, la traducción, el cambio lingüístico; y que constituye un verdadero homenaje a la elocuencia y a las buenas letras. ${ }^{5}$

\section{El sermón y el teatro. La oralidad}

Por otra parte, y en contraste con este aspecto, el sermón participa del ámbito de la oralidad por todo lo que tiene de represen-

\footnotetext{
${ }^{4}$ Apología orada en público concurso en prueba de que conviene que se escriban éstos y otros libros de qualquier facultad en nuestra lengua vulgar Española, del licenciado don Fernando Vallesteros y Saavedra (apud Smith, Preaching, 41). El manual de predicación de Ximénez Patón se titula El perfecto predicador (1612).

${ }^{5}$ Para hablar de los diferentes niveles del cambio lingüístico dice, por ejemplo, que la lengua es semejante a una república, "cuya variación consiste, no en que poco a poco hayan muerto sus primeros ciudadanos, sino en haber mudado de leyes o de gobierno" (Sánchez Vaamonde, 13). Sobre la traducción hace la siguiente reflexión: "Quanto tienen de más delicado los pensamientos y expresiones de los autores que han escrito con toda exactitud y sutileza se pierde al transferirlos a otra lengua; poco más o menos como aquellas esencias exquisitas cuyo sutil olor se evapora cuando se mudan a otro vaso" (210). Un pensamiento delicado, dice: "Es propiamente aquel cuyo primor se esconde a los más y de cuyo autor se puede dudar si trabajó más en proponerle que en ocultarle" (207 y 208).
} 
tación y hasta de espectáculo; y es precisamente en ese ámbito donde constituye, junto con el teatro de esos siglos, el lugar por excelencia del encuentro social y un vehículo para la creación oral del momento. Fue Miguel Herrero García el primero que observó (en 1942) que "el sermón y la comedia eran entonces los únicos centros de reunión de la sociedad culta y los únicos cauces de la literatura oral en España" (Sermonario, xviii).

Pensemos en una corriente continua de influencia recíproca entre el predicador - $\mathrm{O}$ el autor teatral— y su público, donde tienen amplia cabida la improvisación, las referencias a determinadas circunstancias del momento (acontecimientos sociales o políticos, sucesos locales, el desarrollo de los festejos del día, etc.), e incluso la interpelación directa al auditorio. Hay además otro tipo de paralelismos más propiamente textuales que apuntan a la idea de "teatralidad" del sermón: la inserción de diálogos y de apóstrofes, la adaptación del texto al auditorio, el margen para la improvisación, las didascalias y acotaciones de tipo escenográfico que forman parte del texto. La carga de oralidad que comparten ambos géneros se ve también reflejada en el modo de transmisión y reproducción de sus textos: tanto los sermones como las obras teatrales estaban igualmente expuestos a los copistas clandestinos o "piratas" que, una vez escuchado el sermón o la comedia, volvían a casa a copiarlos de memoria (de ahí el sobrenombre de memorillas). Naturalmente, estos personajes harían reelaboraciones más o menos fieles de los textos escuchados, introduciendo en ellos numerosas variantes. ${ }^{6}$

La circulación de estas copias entre la gente de letras era mucho más activa de lo que hoy suponemos. De la popularidad de que gozaban muchos sermones, y de la demanda que llegaban

\footnotetext{
${ }^{6}$ Francisco de Tamayo y Porres memorizó y puso en verso un sermón de fray Antonio de Morato: Sermón en la festividad de San Pedro (Barcelona, 1627), encuadernado con Sermones de santos, de Cristóbal de Avendaño (ver Suarez de Figueroa, Plaza Universal de todas las ciencias, 254 y 255, apud Smith, Preaching, 33).
} 
a tener las copias impresas o manuscritas de algunos de ellos entre el público general tenemos abundantes testimonios; baste con recordar aquí el hecho de que Góngora y sus amigos leían con gran interés e incluso intercambiaban entre ellos copias de sermones ("¡Copias de sermones como de sonetos!", exclama Dámaso Alonso), muchas veces para producir elogios o sátiras de ellos en verso ("Predicadores ensonetados", 97).

\section{El sermón y el comentario. La conciencia del propio oficio}

La amplia repercusión cultural, literaria y social que el sermón alcanzó durante esos siglos debió haber determinado, entre otras cosas, el hecho de que los predicadores agudizaran la conciencia de su propio oficio; fomentando, como diríamos hoy, su orgullo profesional.

En alguna ocasión he señalado la comunidad de recursos que existe entre el género del sermón y el del comentario literario. ${ }^{7}$ Este hecho resulta, a fin de cuentas, muy natural si tomamos en cuenta que el sermón no deja de ser un comentario al texto de las Escrituras y, como tal, está sujeto a la tradición exegética. Entre los recursos compartidos por ambos géneros se encuentran: la necesaria presencia de "autoridades", el uso de la quaestio, el uso de la etimología como prueba, la introducción de digresiones geográficas, genealógicas, científicas, históricas, mitológicas o narrativas, etc. Aquí interesa detenernos un poco en otro de esos recursos, característico tanto del sermón como del comentario: las reflexiones de tipo metadiscursivo, que nos permiten asomarnos a la conciencia del propio oficio y del propio proceder que comparten comentaristas y predicadores. ${ }^{8}$

${ }^{7}$ Cfr. Castaño, "El sermón en España” y "Sermones, explicaciones de arcos".

${ }^{8}$ Smith observó también la presencia de estas reflexiones, que explicó por el hecho de que muchas colecciones de sermones estaban destinadas al uso de predicadores (Preaching, viii-ix). Yo no estoy tan segura, ya que dichas reflexiones 
Es frecuente, por ejemplo, que un predicador se refiera, en el cuerpo mismo de su discurso, a las partes de que consta un sermón. Es el caso del predicador novohispano Bartolomé Felipe de Ita y Parra, que simula empezar su sermón con un exordio sólo para interrumpir su discurso de la siguiente manera: "Dejemos exordios, no perdamos tiempo, si acaso es perderlo dar a los sermones lo que se les debe...". Seis líneas más adelante vuelve a detenerse para hacer una reflexión: "Está propuesta la materia: pidamos la gracia..." (Brading, Siete sermones, 113). También fray Juan Bautista Taboada interrumpe su discurso para señalar a sus oyentes/lectores cómo va construyéndolo:

[...] introducido así y ajustado ya con el evangelio el asunto, y explicada ya también la primera parte del thema... réstanos la segunda... pero así como la primera nos ofreció materia para la salutación, nos la dará la segunda para el sermón, que será con acierto si nos asiste la gracia: Ave María... (etc.) (Taboada, Sermón)

Muchas reflexiones de este tipo se encuentran en la materia preliminar de los sermones impresos (dedicatorias, aprobaciones, pareceres, etc.), como la que hace fray José Jardón en la dedicatoria de su sermón a Luis Morote, en la cual, utilizando una metáfora textil, se pronuncia por la homogeneidad de materia entre dedicatoria y sermón ${ }^{9}$ para, líneas después, subrayar

aparecen por igual en los sermones sueltos, que circulaban entre un público lego y naturalmente más amplio, y además se trata de un rasgo que comparten por igual predicadores y comentaristas, que también escribían para un público relativamente amplio, y que buscaban legitimar su oficio (y su objeto de estudio), encareciéndolo frente a públicos cada vez más diversos.

9 "Tengo creído que las dedicatorias y los sermones se han de vestir siempre de una tela; porque el predicador, si se ajusta a las leyes de la providencia, no ha de sacar de la tienda de los libros tan escasa la tela de que ha de vestir sus sermones que no sobre de la tela del sermón un retazo siquiera, por si se ofreciere vestir una pobre dedicatoria, que así excusa la disformidad de los colores y quita el trabajo a los sastres de la oratoria, que si advierten el remiendo, le han de cortar el vestido de una pieza" (Brading, Siete sermones guadalupanos, sermón 1). 
un paralelismo estructural entre ambos..$^{10}$ Más adelante volveremos sobre este rasgo característico de los paratextos de los sermones impresos.

\section{La forma del sermón}

A pesar de que ni en la Nueva España ni en la Península se contaba con una precisión terminológica que distinguiera con claridad entre sermón, tratado, homilía, comento, plática, oración evangélica, discurso predicable y otras denominaciones aplicadas a colecciones de sermones, tales como "Despertador cristiano", ${ }^{11}$ los cultivadores del sermón en estos siglos, como hemos visto, parecen haber estado bien conscientes de que trabajaban con un género que se distinguía por tener una estructura más o menos precisa. Y se distinguía no sólo en el sentido de que se podía identificar y diferenciar frente a otras formas parecidas de discurso sino, sobre todo, por el prestigio y la autoridad que le eran concedidos a esta forma específica de la oratoria sagrada por un público compuesto de letrados y conocedores, autoridad que, desde luego, también era reconocida por el público de las clases populares.

10 “" [...] me determino a formar esta dedicatoria en el Molde de un sermón. Para éste busca el predicador, en el santo, el blanco de los elogios; para aquélla solicita el agradecido en el Mecenas el sujeto de los afectos" (Brading, Siete sermones guadalupanos, sermón 2).

${ }^{11}$ Un ejemplo: ya en pleno siglo XVII fray Hortensio Paravicino testimonia la paulatina imposición del término sermón sobre el equivalente de Oración Evangélica al comenzar así su Sermón de Santa Isabel (1625): "Esta Oración Evangélica, o Sermón (como quiere el uso común, hábito tan imperioso en las voces que suele hacerse tirano de ellas)". El editor moderno pone la siguiente nota: "Parece, en efecto, que la palabra sermón no se había impuesto totalmente para designar la Oración Evangélica que se predicaba ante un auditorio. En 1588, Fray Pedro Malón de Chaide lo empleaba como sinónimo de tratado para su Libro de la Conversión de la Magdalena" (Paravicino, Sermones, 153). Para el análisis cuidadoso de la diferencia entre sermón y tratado en este pasaje de Malón de Chaide - y con referencias precisas-, ver Smith, Preaching, 42-50. 
Partiendo del hecho bien conocido de que todo sermón tiene como objeto comentar un pasaje de las Escrituras, esta "estructura más o menos precisa" a que nos hemos referido (la particular forma, o dispositio, del género) deriva del sermón universitario medieval, también llamado sermón artístico o escolástico, del que el género conserva algunos rasgos que permanecen razonablemente constantes a lo largo de los siglos, y es tan característica y fácil de reconocer que se presta a la parodia. ${ }^{12}$ Incluso en una época tan tardía como lo son las últimas décadas del siglo XVIII en la Nueva España, sigue habiendo una conciencia tan viva del molde (clásico o tradicional) del sermón, en sus rasgos esenciales, que al parecer sigue siendo el utilizado por la mayoría de los oradores sagrados (al menos aquellos cuyos sermones nos han llegado): tras comenzar con un breve exordio que introduce o declara la letra del evangelio del día o de un pasaje de las escrituras y concluye con una salutación (Ave María), se introduce la narración del sermón, que parte siempre de un thema, por lo general un versículo de las Escrituras, que luego se divide - $\mathrm{y}$ muchas veces se subdivide- en varios puntos que se van desarrollando, o cuestiones que se van probando con autoridades, argumentos, ejemplos. La última parte suele consistir en una confirmación, redondeo o recapitulación de lo dicho en el sermón, para concluir con una invocación a Dios o a la Virgen, y una peroración (exhortación y despedida al auditorio).

12 "What distinguishes this genre is a particular form, or dispositio, which remains fairly constant throughout the history of preaching and lends itself to parody by virtue of being quite easy to recognize. There is always a single main text (thema), and always a division of the text, traditionally a tripartite one in honour of the Trinity: [...] There may of course be several divisions and subdivisions, and critics of the scholastic sermon quote gleefully actual or imagined cases of division by words, or even by letters. [...] Within the basic sermon framework - text and division supported by 'proofs' and 'applications' - there is room for a great deal of diversity" (Smith, Preaching, 44 y 45). Y poco antes: "[...] a sermon is the more concentrated way of expounding a Gospel text, and it may be recognized as a sermon in that it proposes and illustrates a certain thematic or propositional unity" (43). 
El esquema básico (texto — thema-y divisiones apoyadas en "pruebas" y "aplicaciones") es susceptible de todo tipo de modificaciones, lo que llevó a los tratadistas a distinguir entre diferentes tipos de sermones (Smith, Preaching, 45-46). Pero, al margen de tipologías y precisiones teóricas, interesa resaltar aquí la idea general que de este arte tenían los predicadores y hombres de letras de aquellos siglos, y los esfuerzos que hacían para deslindarlo de otros menos refinados o especializados, tales como la homilía, el "comento," el tratado o la paráfrasis. Para ello se referían, de una u otra manera, a su estructura, pero evitaban meterse en demasiadas consideraciones formales. A veces lo hacían aproximándose a la noción por la vía negativa: "Quien expone el Evangelio cláusula por cláusula, sin reducirlo a unidad, hace o paráfrasis, o comento, mas no oración o sermón" (Suárez de Figueroa, El Pasajero, 145, apud Smith, 44). ${ }^{13}$

Es elocuente la manera como José de Ormaza, en el capítulo VIII de su Censura de la elocuencia [Zaragoza, 1648], explica la organicidad del sermón mediante una analogía con el cuerpo humano. En su tratado no propone un "Arte" para hacer sermones ni sugiere esquemas fijos, por generales que sean. Por el contrario, evita todo tipo de precisiones acerca de la estructura $^{14}$ sin dejar por ello de hablar de "la arquitectura" (o de la anatomía) de la "oración eclesiástica". Le preocupa sobre todo subrayar la complejidad y el carácter orgánico de su estructura, insistiendo en que el solo hecho de hilvanar citas bíblicas y pa-

\footnotetext{
${ }^{13}$ También en Smith (44), que observa: "The absence of any kind of structure or subordination to a chief proposition leads Fray Pedro de Valderrama to admit that his Ejercicios Espirituales are not 'sermones hechos, ni con tal intento se escribieron, sino tratados y ejercicios, donde cada uno puede ejercitar su ingenio [...]. Y así verán que no tienen salutaciones, ni introducciones formadas, sólo es un juntar de material, para que labre cada uno la casa, y le dé forma y traza conforme al sitio donde la ha de edificar'”. Ejercicios espirituales para... la Cuaresma, ii [Madrid, 1604].

${ }^{14}$ El título de su capítulo VIII reza: "Donde en confusas líneas se idea la arquitectura del Sermón". Y luego anuncia: "Porque más claro se vea que ai más que dezir lugares en un Sermón, advertiré confusamente sus partes”, etc. [Subrayados míos].
} 
trísticas ("lugares") no puede llevar nunca a la construcción de un sermón, ya que éste, como el cuerpo humano, debe constar de la proporcionada relación entre sus partes: cabeza (constituida por una cita de las Escrituras), miembros (las razones humanas y divinas), sangre, nervios, y hasta espíritu y alma. José de Ormaza echa también mano aquí, con cierta gracia, de una metáfora alimenticia (muy común en la literatura patrística, a partir de san Pablo, y en los comentarios literarios, a partir de Dante, para referirse al texto y al comentario):

El cuerpo de la Oración Eclesiástica consta quizá de más miembros que el cuerpo humano; si no le dan más que uno, ni aun monstruo llegará a ser, sino un pedazo informe. Sea, pues, la cabeza deste cuerpo un assumpto cuerdamente brioso [...] luego la Escritura claro está que la hemos de poner sobre la cabeça ${ }^{15}[\ldots]$. El miembro que crece a ser mayor que el cuerpo no sólo es feo sino inútil: de donde se ve quánta monstruosidad es que todo el sermón sea lugares [citas de las escrituras], como oi los vemos. Estas noticias vayan muchas veces digeridas y echas sustancia del discurso. No fiemos tampoco de nuestra razón que siempre ande en boca de otros. Mas los eruditos de estómago no digieren, sino bomitan las noticias con asquerosas arcadas, del modo que las tragaron. Los otros miembros deste cuerpo son las razones ya humanas, ya divinas, tomándose a braços con los vicios y ajustando con ellos cuentas [...]. De todos estos miembros han de ser sangre y nervios las razones, sentencias, invectivas, apóstrofes, reprehensiones, exortaciones, afectos, animado todo de espíritu alentado, de ingenio mañoso, cuyo discurso ha de ser el alma de todo el cuerpo: assí será perfecto, hermoso y fuerte con la proporción de miembros. ¿Miren pues si ai más que hazer en el Sermón, que hilbanar lugares?

Hemos visto que los textos preliminares que acompañan a los sermones escritos también suelen hacer eco de esa estructu-

\footnotetext{
${ }^{15}$ Alude al thema o texto bíblico con que comienza un sermón.
} 
ra, como haciéndole homenaje y servicio, constituyéndose muchas veces en una especie de réplica de la forma y del contenido de los sermones a los que sirven de introducción. Se diría que su principal función fue la de hacer una reflexión que subrayara esa estructura ya cristalizada que fue como la seña de identidad del género durante varios siglos. Al revisar los sermones novohispanos publicados durante esos siglos se pone de manifiesto con cuánta frecuencia esos textos preliminares resaltan el tema y la estructura del discurso que introducen, produciendo un efecto parecido al que produce un tramoyista cuando dirige el reflector al actor principal para acentuar ciertos momentos de una obra teatral. O bien, podría ser que la estructura del sermón, tan decantada y prestigiada a lo largo de los siglos, tuvo tal fortuna que pasó a contaminar también las dedicatorias, censuras, pareceres y demás elementos paratextuales que acompañaban a las piezas publicadas. Pero, independientemente de las causas de este fenómeno, interesa destacar aquí un dato importante que viene a reforzar aún más la idea de la relación entre sermón y literatura anunciada en el título: en estos textos preliminares se presta invariablemente más atención a cuestiones de estructura y estilo que a cuestiones teológicas o doctrinales; es decir: en general este tipo de textos resaltan los aspectos literarios del sermón por encima de sus valores de adoctrinamiento moral.

\section{La figura del predicador}

La imagen que se tenía del predicador no sólo como autoridad moral, sino también como autoridad intelectual, como literato y creador, se refleja igualmente tanto en los preliminares como en el texto del sermón. A continuación voy a referirme a algunas de estas imágenes del predicador que he encontrado en sermones mexicanos de los siglos XVII y XVIII. La primera corresponde con el tópico del predicador como hombre docto y santo, en 
clara correlación con los tópicos clásicos del docto poeta y del probo orador. Esta imagen del predicador debe considerarse, como se hacía en la época, a la luz de las teorías sobre los diversos tipos de ingenios plasmadas en la obra de Huarte de San Juan, así como a la luz de las constituciones prácticas de varias órdenes religiosas (Smith, Preaching, 24 y 25).

Mediante un esquema que no deja de tener sus analogías con ciertos clichés actuales en torno a la relación entre el autor "académico" y el escritor "profesional", Huarte de San Juan —que carga con toda una tradición de conocimientos protocientíficos, sobre todo de medicina, pero también de sentido común- opone al ingenio "teórico" (el teólogo escolástico) el "práctico" (el predicador). El primero, dice el médico humanista del siglo XVI, "sabe la razón de lo que toca a su facultad"; el segundo "las proposiciones averiguadas y no más"; y, con esta base, Huarte señala el peligro que entraña que el predicador, careciendo de la potencia con que se saben de raíz las verdades, tenga autoridad de enseñar al pueblo la verdad, y el pueblo obligación de creerle. El teólogo podía tener las "credenciales" para discurrir con plena autoridad sobre los más arduos problemas teológicos, pero, por otra parte, el radio de influencia inmediata y de incidencia social del predicador era muchísimo más amplio. Por todo ello, no debe extrañarnos, como apuntaba Smith, el hecho de que tantos famosos predicadores — que muchas veces eran titulares de cátedras universitarias - se esforzaran continuamente por probar su competencia como teólogos, y que —al igual que los autores de artes de predicar - subrayaran, a cada oportunidad, el carácter enciclopedista del conocimiento necesario para componer sermones. Y éste es otro aspecto compartido por los comentaristas de poesía cuando se refieren en términos muy semejantes a las cualidades que deben tener los de su oficio. ${ }^{16}$

\footnotetext{
${ }^{16} \mathrm{El}$ anónimo autor del siglo XVII que escribió en México su Arte breve para hacer sermones, conservada en manuscrito en la Biblioteca Nacional de México, (Ms. 36 BNM) dice también que: "Para ser grande escripturario (si quieres serlo) y
} 
Por otra parte, a la faceta del predicador como moralista - y, por metonimia, como hombre virtuoso: el santo predicador/ probo orador - corresponden algunas imágenes de tipo metafórico, presentes en los sermones de la época. Una de ellas es la del predicador y su sermón como "los ojos y la luz" de su comunidad. Veamos un ejemplo: Antonio Ponce de León, capellán y prosecretario del obispo de Michoacán, en un sermón predicado el día de San Miguel, con motivo del estreno de una nueva y costosa lámpara, donada por los señores del cabildo para la catedral de Valladolid, ${ }^{17}$ compara al arcángel Miguel con Argos:

Es Miguel ojo del cordero. No tiene, como el mentido Polifemo, sólo un ojo, antes Argos sagrado, se hace ojos para alumbrar, a fuer de lámpara, en todas partes y a todas luces; por eso, si de Argos cantó Ovidio que tenía en 100 ojos 100 luces [...] esta hermosa lámpara, copia del Argos Miguel, tiene con la de en medio cien luces. ${ }^{18}$

tener mucha Copia de lugares en prompto: es menester que hurgues y juegues a muchos Vissos la Escriptura y para eso es necesario que sepas muchas exposisiones de P.P., muchas y diversas Verciones, muchos simbolos, sombras, y figuras de la Santa Scriptura, que mires lo antecedente, concomitante y consequente de dichos lugares: el tiempo, el lugar, las Personas, y sus nombres o de estos su significado: Y si tubieres estudiosa observacion de esto, a buen seguro, se te descubrira espacioso Campo para adequacion de tu ministerio" ("Modo de fecundarse en la ynteligencia de la Escriptura", § 10). Por su parte, Bartolomé Jiménez Patón había dicho: "El teólogo sólo profesa Teología, más el predicador no será perfecto si después de ser sabio en Teología no tiene noticia de las matemáticas, y es en Retórica de buen lenguaje y acción. Cánones y Leyes sabe, de la Música entiende, de la Historia no ignora, de Medicina tiene principios, en Cosmografía y Geografía es muy perspectivo, y con esto se halla en él gran fe, caridad, prudencia, bondad y santidad" (Elocuencia española en Arte, Toledo, 1604, fo. $3 \mathrm{v}^{\mathrm{o}}$, apud Smith, Preaching, 25 y 26).

${ }^{17}$ La lámpara de los cielos el glorioso arcángel san Miguel. Sermón panegírico que en su día 29 de septiembre de 1735 en que se dedicó la costosa y primorosa lámpara en la Santa Iglesia Catedral de Valladolid, predicó en ella el Br. Joseph Antonio Eugenio Ponce de León, capellán y prosecretario de visita del Ilmo. y Rmo. Sr. Obispo e Michoacán [...]. En México por Joseph Bernardo de Hogal, 1735.

${ }^{18}$ Esta imagen cobra todo su significado gracias a la introducción de este sermón, en la que el predicador nos narra la anécdota de su personal encuentro y meditación con la vela que alumbra su mesa, cuando intentaba reunir fuerzas para empezar a escribirlo. 
Ponce de León establece el concepto en torno al cual va a girar el sermón: apoyándose en la autoridad de san Juan, establece la analogía de san Miguel con una lámpara. La nueva lámpara de la catedral de Valladolid tiene cien luces y, como ella, san Miguel es una lámpara de cien luces. A continuación, como hemos visto, el predicador establece la analogía del santo con Argos, que tiene cien ojos. En la misma tesitura, los autores de los dos "pareceres" que preceden al sermón, Joseph de Eguiara y Eguren y Juan de Mercado, continúan el desarrollo del concepto, equiparando el sermón mismo con una lámpara de cien luces, y a ambos — sermón y lámpara — con la figura de Argos, el guardián de los cien ojos, inmortalizados en los ojos del plumaje del pavo real. ${ }^{19}$

La imagen de Argos con sus cien ojos como emblema del texto (del sermón) había sido aplicada también a las glosas o comentarios - y esta es otra analogía entre ambos géneros- por don Pedro de Portugal en las cien glosas a su Sátira de felice e infelice vida (circa 1450), donde llama a aquellas "hijas del texto", al que compara con "Argos" por tener cien de ellas. ${ }^{20} \mathrm{En}$ la segunda glosa, tras narrar con detenimiento la historia que se encuentra en Ovidio (Metamorfosis, I), señala que Argos representa la prudencia, y de allí pasa a hacer la apología de su propio oficio de comentarista: "e asy como el ojo corpóreo al cuerpo alumbra e guía, asy la glosa al testo por senblante manera faze, quitando dudas a los leyentes. E asy como el ojo da trae e causa

${ }^{19}$ Dice Eguiara y Eguren: “[...] me parece estar viendo en él [sermón] una bien torneada lámpara por el artificio y el ingenio que lleva en su juiciosa contextura y disposición, tan ajustada a la Oratoria". Y poco más adelante habla de "el azeite de las buenas letras que ha sabido alambicar el estudio del autor".

20 "Fize glosas al testo, aunque no sea acostumbrado por los antiguos auctores glosar sus obras. Mas yo, movido cuasi por neçessidat, lo propuse fazer, consierando que, syn ello, mi obra parecería desnuda e sola, e mas causadora de quistiones que no fenesçedora de aquellas [...]. Et, llegando al puerto por mi desseado, leyendo que era tiempo convenible, quise enviar la madre con sus fijas a la vuestra muy serena virtud. [...] reçebid esta mi Argos, e reçebid esta indigna sierva vuestra que, besando las manos reales, goze de la muy desseada vista” (Portugal, Sátira, 9 y 10). 
gozo e alegria, asy la glosa alegra, satisfiziendo a lo obscuro, e declarando lo oculto" (Portugal, Sátira, 12)

Para finalizar me referiré a otro de los tópicos que ilustran la idea de la predicación que prevalecía en aquellos siglos y que, una vez más, refuerza la analogía entre el sermón y el comentario. Se trata de la importancia que se les atribuye a ambos no sólo para dar lustre al texto, sino para concederle una existencia, además de oficial, duradera, incluso eterna. En el caso de la predicación, el texto no es siempre ni exclusivamente las Escrituras, ya que, aunque se sirva de ellas, muchas veces el objeto principal de un sermón es un acontecimiento específico (nacimientos, muertes, matrimonios, coronaciones, profesiones de monjas o sacerdotes), un personaje (sobre todo gente de la nobleza, gobernantes, funcionarios eclesiásticos), una fiesta religiosa o cívica, e incluso un objeto importante o sagrado. Mediante su experto conocimiento y uso de la palabra, el predicador tiene el poder de otorgar lustre e inmortalidad a los personajes, acontecimientos y objetos de que habla con la debida maestría en su sermón, revistiéndolos de una rica significación, al igual que el comentarista hace con las obras literarias.

Miguel Romero López de Arvizu, editor del sermón de La lámpara de los cielos, escribe una extensa dedicatoria del mismo al obispo de Michoacán, donde subraya el poder de la palabra (específicamente de la palabra impresa y —lo que más le interesa al editor - de quienes la producen y la patrocinan) para conceder fama, larga vida y hasta para inmortalizar. En su encarecimiento de la letra impresa, Miguel Romero llega a decirle al obispo de Michoacán que, si la lámpara del Tabernáculo de Israel se mantendrá siempre encendida — como en su momento ordenó Dios a Moisés (Éxodo, XXVII)—, es gracias a que su descripción ha llegado hasta nosotros impresa en el libro del Éxodo:

Hizo Dios a Moisés tesorero del Tabernáculo [... y y en llegando a la lámpara $[\ldots]$ le mandó que sus esplendores siempre lucieran: [...] Sí lucirá con las demás alhajas, pues su descripción se 
imprimió en los capítulos del Éxodo (apud Ponce de León, La lámpara de los cielos, Dedicatoria, s/f).

De la misma manera, la flamante lámpara que acaba de estrenar la catedral de Valladolid en México podrá lucir eternamente, y su fama y significación durarán por siempre, gracias al sermón de Ponce de León, que nos la ha dejado descrita en toda su gloria, revestida de toda una gama de valores simbólicos ya indisolublemente asociados al arcángel san Miguel. El editor del sermón agradece a los miembros del cabildo de la catedral de Valladolid el patrocinio de la gran lámpara, comparando el inagotable celo y caridad de los prelados con el aceite bíblico que eternamente se renueva, recurriendo a la etimología como prueba - otro recurso compartido por sermón y comentario- $-{ }^{21}$ Luego viene la dedicatoria formal, en la que ensalza al sermón, llamándolo "racional lámpara", por "la filigrana de sus conceptos, labrados al martillo de su notorio estudio", pues gracias a él podrá inmortalizarse el recuerdo de la lámpara real en molde. ${ }^{22}$

En estas líneas me he referido sólo a unas cuantas imágenes del predicador y de su oficio que circulaban ampliamente en los sermones del México colonial. Sirvan como invitación para

21 "Valle de Olivas es, en sabida etimología, Valladolid; óleo es la caridad y zelo: pues con el de V.S.Ilma. y los señores prebendados serán inextinguibles los esplendores de la lámpara [...]; que si de una se escribe que sin refaccionarla de azeite, ardió siglos enteros [Vegencio, in Vita Santae Catharinae] fue tanto el de el zelo con que la nuestra se hizo, que por siglos enteros estará en su duración flamante el lucimiento de V.S. Ilma. Y los señores capitulares, que fieles administradores de la fabrica, la erigieron" (apud Ponce de León, La lámpara de los cielos).

22 " [...] por eso yo les dedico la luzida lámpara de este sermón, como a principales autores de la que en él doctamente se describe, sin desinteresarme de la gloria que me resulta de haberse fabricado en mi tiempo, ni sacar de parte al orador de este sermón, pues tiene tanta prenda en nuestro gozo, como recomienda aver hermoseado la Lampara con la filigrana de sus conceptos, labrados al martillo de su notorio estudio, el que nos facilita inmortalizar el recuerdo de esta obra en el molde, de que es tan digna su racional lámpara, siéndolo él, como destello de la familia lucida de V.S: Ilma." (apud Ponce de León, La lámpara de los cielos). 
seguir haciendo calas en ese acervo tan rico como poco explorado que son los sermones de la época conservados en el Fondo Reservado de la Biblioteca Nacional de México. Tomemos en cuenta que la trascendencia literaria del sermón, también en tierras americanas, aún no ha sido suficientemente aquilatada, y que su comprensión cabal abrirá todavía más de una veta en nuestros estudios literarios. 


\section{REFERENCIAS}

Anónimo, Breve arte para hacer sermones, s/l, s/f. Ms. Biblioteca Nacional de México.

Alonso, Dámaso, "Predicadores ensonetados", en Del Siglo de oro a este siglo de siglas, Madrid, Gredos, 1962, 95-104.

BRADING, David (selec., estud. e introd.), Siete sermones guadalupanos (1709-1765) [1993], México, Centro de Estudios de Historia de México Condumex, 1994.

CAstaÑo, Ana, "El sermón en España durante los siglos XV y XVI (algunos rasgos del género)", Acta Poetica, 21, 2000, 217-227.

__ "Sermones, explicaciones de arcos y comentarios literarios: géneros afines en el contexto de la fiesta novohispana", en Reflexión y espectáculo en la América virreinal, Universidad Nacional Autónoma de México, Instituto de Investigaciones Bibliográficas, 2007, 187-201.

Cátedra, Pedro (ed.), Sermón, Sociedad y Literatura en la Edad Media. San Vicente Ferrer en Castilla (1411-1412), Salamanca, Junta de Castilla y León, 1994.

Herrero García, Miguel, Sermonario clásico, Madrid-Buenos Aires, Escelicer S.L., 1942.

Olmedo, Félix, "Prólogo" a Fray Dionisio Vázquez. Sermones, Madrid, Espasa-Calpe, 1956, IX-LXIV.

Ormaza, José de, Censura de la elocuencia [Zaragoza, 1648], Giuseppina Ledda (introd. y texto), Madrid, El Crotalón, 1985.

Paravicino, Hortensio, fray, Sermones cortesanos [1616-1633], Francis Cerdan (ed., introd. y notas), Madrid, Castalia, 1994.

Ponce de León, Eugenio, La lámpara de los cielos el glorioso arcángel san Miguel. Sermón panegírico que en su día 29 de septiembre de 1735 en que se dedicó la costosa y primorosa lámpara en la Santa Iglesia Catedral de Valladolid, predicó en ella el Br. Joseph Antonio Eugenio Ponce de León, capellán y prosecretario de visita del Ilmo. y Rmo. Sr. Obispo e Michoacán, su vicepromotor iscal: y catedrático que fue de Philosophia en el Real Colegio del Sr. San Nicolas Obispo, de dicha Santa Iglesia... Sácalo a la luz el Dr. Miguel Romero Lopez de Arbisu, substituto que fue de la cátedra de sexto en cánones en la Universidad de 
Zaragoza... quien lo dedica Al Ilmo. Señor Doctor Don Juan Joseph de Escalona, y Calatayud, del Consejo de su Majestad, su dignísimo obispo de Michoacán, y a los señores Venerable Dean, y Cabildo de la Sta. Iglesia Catedral de Valladolid. En México por Joseph Bernardo de Hogal, 1735.

Portugal, Pedro de, Sátira de felice e infelice vida, en Obras Completas do Condestável Dom Pedro de Portugal, Luis Adao da Fonseca (introd. y ed.), Lisboa, Fundación Calouste Gulbenkian, 1975.

Rico, Francisco, Predicación y literatura en la España medieval, Cádiz, Universidad Nacional de Educación a Distancia, 1977.

Romero López de Arvizu, Miguel, Dedicatoria (ver Ponce de León). SÁnchez VaAmonde, Pedro Antonio, Discurso sobre la elocuencia sagrada en España, Madrid, Imprenta de Blas Román, 1778.

SMith, Hillary Dansey, Preaching in the Spanish Golden Age, Oxford, Oxford University Press, 1978.

TABoAda, Juan Bautista, Sermón que en la publicación de el edicto general de la fe, en la iglesia parrochial de la villa de Pintzandaro, la Dominica tercera de cuaresma año de 1714 predicó el P. Fr. Juan Baptista Taboada, actual lector de Teología en el colegio de la Purísima Concepción de Zelaya... México, por los herederos de la viuda de Francisco Rodríguez Lupercio, en la Puente de Palacio, Año de 1715.

Terrones del Caño, Francisco, Instrucción de Predicadores [Madrid, 1617], Félix de Olmedo (ed. y pról.), Madrid, Espasa-Calpe, 1946.

Vicente Ferrer, Sermón, Sociedad y Literatura en la Edad Media. San Vicente Ferrer en Castilla (1411-1412), Pedro Cátedra (estudio bibliográfico, literario y edición de los textos inéditos), Salamanca, Junta de Castilla y León, 1994. 